\title{
On the assessment of autoignition delay for Diesel fuel and Biodiesel B20
}

\author{
Bogdan Radu ${ }^{1, *}$, Alexandru Racovitza ${ }^{1}$, and Radu Chiriac ${ }^{1,2}$ \\ ${ }^{1}$ University POLITENICA of Bucharest, Faculty of Mechanical Engineering, Romania \\ ${ }^{2}$ Associated Member of CMGPCE-EA7341, CNAM, 292 rue St-Martin, 75003, Paris, France
}

\begin{abstract}
The use of bio-fuels is a necessity nowadays, regulated by European legislation, which imposes to the EU-countries an increase in the substitution rate of classic fossil Diesel fuel. Biodiesel (B) fuel proves to be a reliable agent to fulfil this requirement, but a certain number of aspects have to be ameliorated regarding the compatibility of this kind of fuel with the existent compression ignition engines. One of these problems relies on the autoignition delay, on which the research results are still dispersed. The paper proposes an analysis of this autoignition delay when using a compression ignition $(\mathrm{CI})$ engine fuelled with Diesel fuel and with blends of Diesel and Biodiesel fuels (B20 - 20\% volumetric fraction of Biodiesel), starting from several correlations given by the literature, which are based on single-cycle analysis and application of the integral Livengood-Wu method. The obtained results offer an image of the in-cylinder processes complexity and of the B20 fuel behaviour related to the tested engine operation.
\end{abstract}

\section{Introduction}

Biofuels as an alternative to classical petroleum derived fuels mixed in different fractions have become increasingly used in the last few decades due to worldwide regulations concerning emissions. Market policies are nowadays encouraging the expanding of biofuels limits in mixtures and their use in an efficient way in internal combustion engines. Among these, combined mixtures of Diesel-Biodiesel and Diesel-BiodieselAlcohols play a more significant role in the whole chain of the cylinder processes, from the injection phase until the end of combustion. Therefore, evaluating and controlling the autoignition period has direct consequences on the global engine performance parameters. It is known that a larger content of alcohol (ethanol or butanol) leads to an increase of autoignition delay because of its lower cetane number $(\mathrm{CN})$ value and to a decrease of the premixed air-fuel temperature due to its higher heating value (ethanol), inhibiting the $\mathrm{NO}_{\mathrm{x}}$ formation, despite its higher molecular content of oxygen; on the contrary, the use of a predominant amount of Biodiesel leads to a decrease of this delay, ensuring a better control of the injection timing in good connection with the main variables defining the engine operation [1-3].

From the whole range of Diesel-Biodiesel fueling mixtures, B20 is a promising prospect regarding a number of evaluation criteria, such as ID (Ignition Delay - see Fig. 1 , defined as the duration between the start of injection, SOI and the start of combustion, SOC [4]), BTE (Brake Thermal Efficiency), soot, $\mathrm{CO}, \mathrm{THC}$ and $\mathrm{NO}_{\mathrm{x}}$ concentrations, peak fire pressure, maximum rate of the firing pressure, according to Multi-Criteria Decision Making method (MCDM) [5]. By using Biodiesel as an additional fuel, it could also become necessary to modify the characteristics of the engine original injection system, to adjust the split-injection arrangement, the nozzle dimension, and the spray patterns, as many studies have proven [6-9].

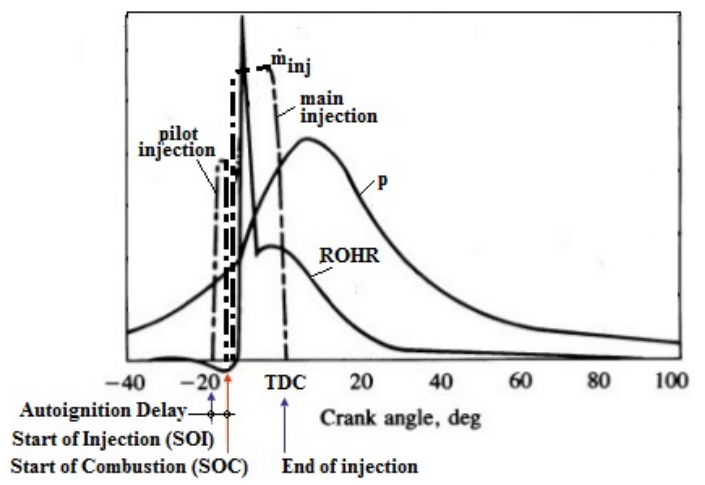

Fig. 1. Pressure $p$, rate of relative heat release (ROHR) and split injection characteristics in a compression ignition (CI) engine cylinder [4].

Many of the approaches used to approximate the autoignition delay are based on Arrhenius correlation and have been proposed in the case of using Diesel fuel [10], but in the case of using Biodiesel fuel there is still a lack of theoretical information. By exception, one formula [11] could be relevant, as its form was properly adjusted as following:

$$
\tau_{i g n}, \mathrm{~ms}=C p^{a} \Phi^{b} C_{n}^{c} \exp \left(E_{A} /\left(R_{M} T\right)\right)
$$

\footnotetext{
* Corresponding author: bobitaradu@yahoo.com
} 
in which $C, a, b, c$ are constants, -, $p$ is the in-cylinder mean pressure, atm, $\Phi$ is the equivalence ratio, -, $C_{n}$ is the length of the carbon chain,,$- E_{A}$ is the activation energy, $\mathrm{kcal} / \mathrm{mol}, R_{M}$ is the gas universal constant $\left(1,987 \times 10^{-3}\right.$ $\mathrm{kcal} /(\mathrm{mol} \cdot \mathrm{K}))$ and $T$ is the in-cylinder mean temperature, $\mathrm{K}$. A particular concern is the calculation of the activation energy, with different values when the fuel content varies [12].

Previous studies [10,13-15] have provided an acceptable similarity between experimental and simulation results, using the AVL-BOOST, AVL-FIRE software tools, with the pressure and the temperature picked as averaged values from a group of successive operating cycles. The present work is based on the analysis of each individual cycle from the acquired batch of consecutive cycles, when discussing pressure and temperature values, applying the Livengood-Wu method [16].

\section{Hypotheses to calculate the autoignition delay}

This paper uses the experimental results obtained by testing a naturally aspirated Diesel engine in tractors. Its main features, together with all the test bed systems have been discussed in a previous work [10]. Using this experimental basis, 200 individual pressure traces have been recorded, for each engine operating condition.

The autoignition delay was firstly determined experimentally and then established by considering a relationship of type (1). There is a large variety of coefficient values to form this expression, the authors propose a diversity of mathematical influences on the result. The presented paper considers the form proposed by Assanis [14], in which the pressure, $p$ is given in bar, $\Phi$ is the equivalence ratio [-] and $T$ is the absolute temperature, in $\mathrm{K}$ :

$$
\tau_{i g n}, \mathrm{~ms}=2,4 p^{-1,02} \Phi^{-0,2} \exp (2100 /(T)) .
$$

The calculation of the engine in-cylinder autoignition delay has two extremely sensitive and difficult to measure components. The first one is the start of injection (SOI), marked by the start of the injector needle lifting. The second one, even more difficult to evaluate, is that of the start of combustion (SOC). This process adds energy in cylinder leading to a pressure increase, its rate being a parameter experimentally recorded.

Paper [13] presents several methods of establishing SOC, by taking into account the 1 st, the 2 nd and the $3 \mathrm{rd}$ derivations of the pressure. Due to the sensitivity of the measurement system and since numerical derivation is an unsteady process, the obtained results were inconclusive.

Another approach consists of the relative heat release (ROHR) calculation. This is given by the sum of the piston mechanical work and the gas internal energy variation, diminished by the heat transferred to the walls during the compression process. At the end of compression both mechanical work and the heat transferred to the walls get negative values, therefore the heat release becomes also negative. It can be assumed that combustion starts corresponding to an angle for which this variable becomes positive and begins to increase.

The calculation of the autoignition delay could be achieved by calculating the pressure and the temperature average values in between a considered range period, or by calculating the relative delay on each such a range; this method is known as Livengood-Wu [16]:

$$
\int_{t 1}^{t 2} \frac{d t}{\tau_{i g n}(t)} \approx 1
$$

where $t_{1}$ is injection time and $t_{2}$ is the value of ignition time. In this equation $t_{2}$ is the unknown value.

These two procedures are practically equivalent, are based on the same principle, but for the second one there is a possibility to conduct a linear interpolation on the last range element to obtain a more precise result. In this paper there will be analyzed 200 individual cycles related to the autoignition delay, for an engine fuelled with Diesel and Biodiesel B20 fuels, when applying one of the proposed autoignition delay correlation and the integration calculus method. At the end of this computation a relative error analysis versus the measured value has also been completed.

\section{Calculation Results}

The measurements on the tested engine have been presented in [10] and listed in Table 1 (by extraction from Fig. 1):

Table 1. Injection and start of combustion angle.

\begin{tabular}{|c|c|c|}
\hline Case number & 1 & 2 \\
\hline Fuel/Speed & Diesel/2400 rpm & B20/2400 rpm \\
\hline SOI & $-5 \mathrm{CA}$ & $-5,5 \mathrm{CA}$ \\
\hline SOC & $0,375 \mathrm{CA}$ & $-0,15 \mathrm{CA}$ \\
\hline
\end{tabular}

where CA is the crank angle and SOC is the angle for the start of combustion.

For these cases the nominal torque was $175 \mathrm{Nm}$, corresponding to a nominal power of $44 \mathrm{~kW}$.

The calculation of the autoignition delay has been developed for each single cycle and for each of them the corresponding angle where the integral (equation (3)) reaches the value 1 has been extracted and listed (see Fig. 2, Case 1).

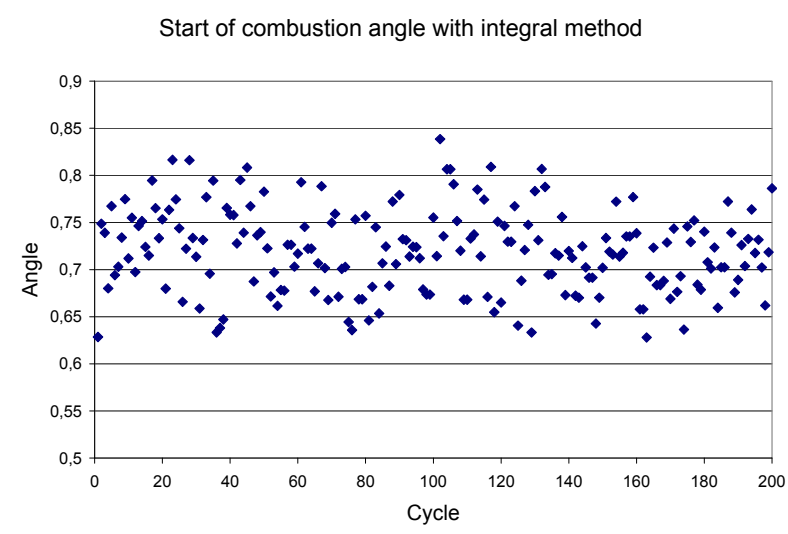

Fig. 2. Ignition angle for Case 1. 
In this case, when the engine is fuelled with Diesel fuel, at full load the relative air-fuel ratio is 1.5. For these operating conditions, the angles for which the integration is 1 are included in the range $0,6 \ldots 0,8$ deg.CA (ATDC, see Fig. 2). The average value for these data is 0,72 deg.CA as compared to the experimental average value of 0,38 deg.CA, there is a difference of 0,34 deg.CA.

Using the experimental data obtained in Case 2, when fuelling the engine with B20 fuel, the results appear more dispersed. For the ignition moment the average value is 0,3 deg. CA, very close comparing to the experimental results $(0,375 \mathrm{CA})$. The experimental data for each individual cycles for start of combustion are located in domain -0,5 and 1,7 deg.CA (see Fig. 3).

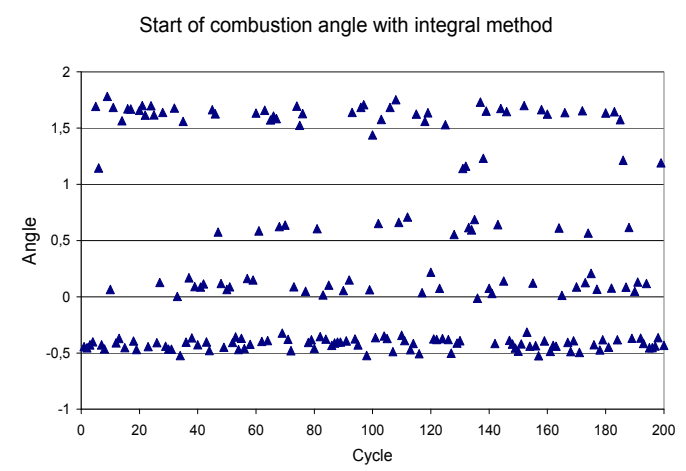

Fig. 3. Ignition angle for Case 2.

To be able to use Assanis's formula with the help of the temperature and pressure average values it is useful to expose them inside a domain of interest limited between SOI and by some points relative to top dead center (TDC). The average values for pressure and temperature from SOI to current position (where end of compression $\mathrm{TDC}=0)$ are listed in Table 2 .

Table 2. Pressure and temperature in cycle.

\begin{tabular}{|c|c|c|c|c|c|c|c|}
\hline Case/CA & -5 & -4 & -3 & -2 & -1 & 0 & 1 \\
\hline Case 1 p & 44,5 & 44,8 & 45,0 & 45,1 & 45,2 & 45,2 & 45,1 \\
\hline Case 1 T & 1017 & 1016 & 1014 & 1012 & 1009 & 1007 & 1003 \\
\hline Case 2 p & 46,1 & 46,3 & 46,5 & 46,6 & 46,7 & 46,7 & 46,6 \\
\hline Case 2T & 1053 & 1051 & 1049 & 1046 & 1043 & 1040 & 1038 \\
\hline
\end{tabular}

From this stage further the autoignition delay values for each range, starting from SOI and reaching -5 deg.CA BTDC are as follows (see Table 3, where $A s$, ms is the value for Assanis formula and $d t$, ms is time elapsed from the SOI angle; in this table are presented only the values around top dead center, respectively $-1,0,1$ degree):

Table 3. Time evaluation for average values.

\begin{tabular}{|c|c|c|c|c|c|c|}
\hline & \multicolumn{2}{|c|}{$-1 \mathrm{CA}$} & \multicolumn{2}{c|}{ 0CA } & \multicolumn{2}{c|}{ 1CA } \\
\hline & $A s$ & $d t$ & $A s$ & $d t$ & $A s$ & $d t$ \\
\hline Case 1 & 0,42 & 0,34 & 0,42 & 0,41 & 0,42 & 0,48 \\
\hline Case 2 & 0,38 & 0,34 & 0,38 & 0,41 & 0,38 & 0,48 \\
\hline
\end{tabular}

For the analyzed engine operating conditions, applying the proposed formula, the average values define SOC in the range of $-1 \ldots 0$ deg.CA in the case of Biodiesel and in the range $0 \ldots 1$ deg.CA in the case of Diesel fuel, values to be found also in most of the individual cycles.
Another analysis mode is that in which for each single cycle the adopted average values for temperature and pressure are those calculated for the period following SOI. When fuelling with Diesel (Case 1), this procedure offers values that are relatively close to the results obtained with the integral method, the average value for the integral is $0,72 \mathrm{CA}$ and for the other calculation 0,69 CA (see Fig. 4).

Start of combustion angle with both methods

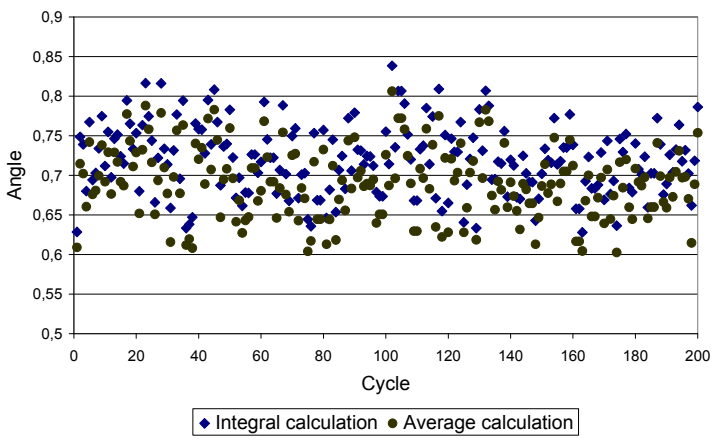

Fig. 4. Results for Case 1.

Comparing these two procedures is possible in the mean cycle obtained as an average of the 200 individual cycles. Averages for temperature and pressure are those obtained by calculating the averages over the 200 cycles and these ones resulting from the range values situated between SOI and the adopted angular limit after TDC.

Fig. 5 presents the cylinder pressure and temperature traces for the values involved in the Case 1 calculation. The mean trace represents the average values over the 200 consecutive cycles and the average trace is obtained from the values starting from the injection point.

Temperature and pressure

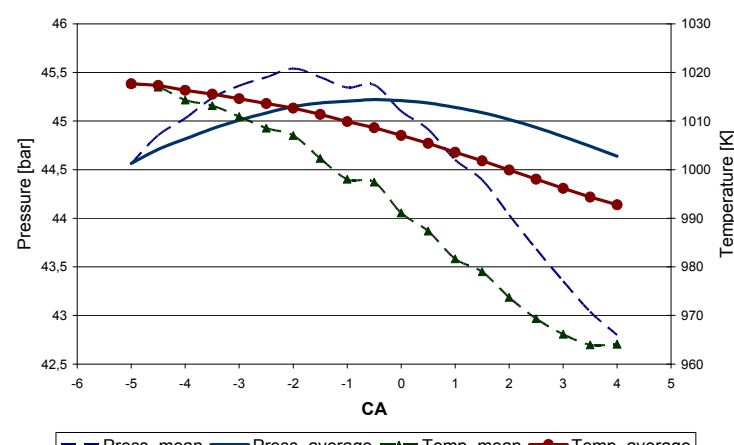

Fig. 5. Pressure and temperature traces for calculation Case 1.

Calculations were made with the following correlations (4):

$$
p_{\alpha \text { mean }}=\frac{1}{200} \sum_{1}^{200} p_{\alpha i},
$$

where $p_{\alpha i}$ is the pressure measured at angle $\alpha$ for each individual cycle.

In order to use the Assani's formula it is necessary to define the average values for cylinder pressure and temperature in the ignition delay period. These values are calculated with the correlation (5): 


$$
p_{\alpha \text { average }}=\frac{1}{\alpha_{i n j}-\alpha} \sum_{\alpha_{i n j}}^{\alpha} p_{\alpha}
$$

where $\alpha_{i n j}$ is the injection angle. The temperatures are calculated with the same relations.

When we plot both methods on a single diagram, we obtain insignificant differences which lead to the decision that both could be applied with same degree of certainty (see Fig. 6).

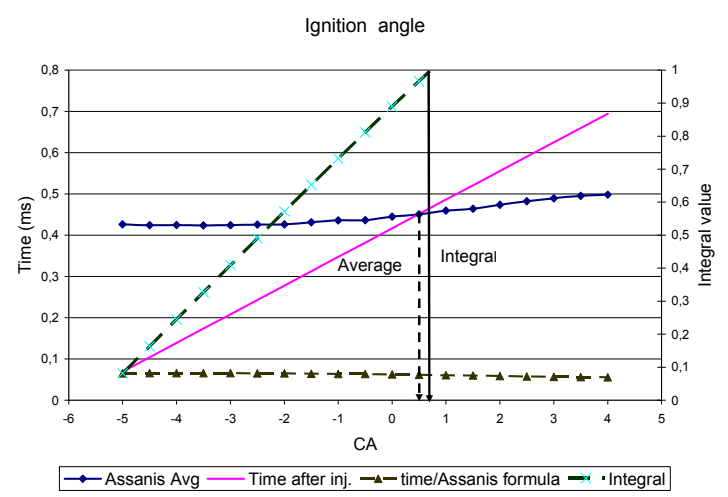

Fig. 6. Example calculation for both methods for Case 1.

When fuelling with B20 fuel, the use of the average values related to the autoignition delay reduces the dispersion of the results obtained by integration method. Using this second procedure, the range of the ignition angles becomes 0 ... 0,5 deg.CA (see Fig. 7.).

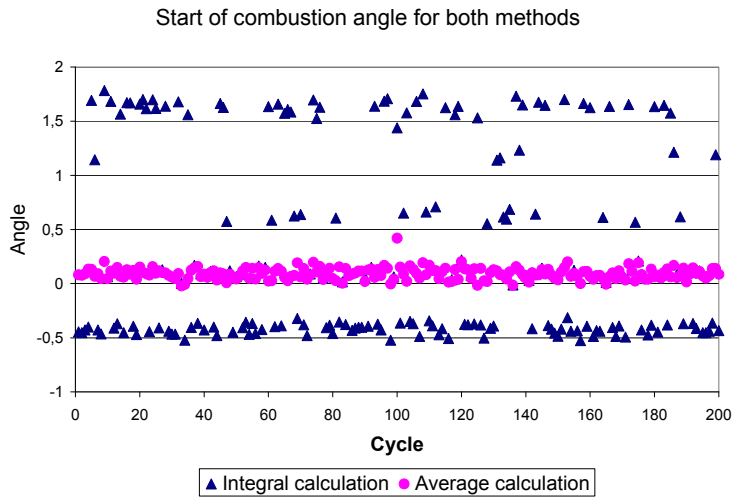

Fig. 7. Results obtained for Case 2.

In terms of the mean values obtained over 200 cycles applying both methods/procedures, the results on the SOC angle for both cases are listed in Table 4.

Table 4. Mean values of SOC angle for both cases.

\begin{tabular}{|c|c|c|}
\hline & Integral calc. & Average calc. \\
\hline Case 1 & 0,71 & 0,69 \\
\hline Case 2 & 0,29 & 0,10 \\
\hline
\end{tabular}

\section{Conclusions}

The paper presents experimental data obtained when fuelling a tractor Diesel engine with Diesel and B20 Biodiesel-Diesel B20 mixture (20\% vol. Biodiesel). An analysis was made to evaluate a simple calculation relationship for the autoignition delay (Assanis), depending on the in-cylinder pressure, the global uniform temperature during the autoignition delay period and the air-fuel ratio for the analyzed operating condition.

In this computation individual cycles were used, for each of them two mathematical evaluation methods have been proposed: integrating the autoignition delay relative time and evaluating the average values of temperature and pressure on a certain angular range.

The results show small differences between the two calculation modes of the autoignition delay, lower than 0,5 deg.CA.

The cyclic variability caused probably during the compression process by the variation of the inlet process combined with the different air-fuel mixture formation in case of B20 leads to an increased dispersion of SOC.

The differences calculated for both types of fuels are inside the variability domain, consolidating the conclusion that from the perspective of the autoignition delay the behaviour of these two fuels (Diesel and B20) is practically the same.

The existing deviations of the theoretical results relative to the experimental data obtained for the two different fuels range between 0,25 to 0,5 deg.CA.

This study will be continued by analyzing other engine operating conditions to extend the soundness of these conclusions.

\section{References}

1. M. Lapuerta, J. Hernandez, D. Rodriguez, A. CovaBonillo, Autoignition of blends of n-butanol and ethanol with Diesel or Biodiesel fuels in constantvolume combustion chamber, Energy, 118, 613-621 (2017)

2. A. Jamrozik, W. Tutak, M. Pyrc, M. Sobiepanski, The effect of Diesel-Biodiesel-Ethanol blend on a direct injection Diesel engine, Thermal Science, 21, 591-604 (2017)

3. D. Alviso, F. Krauch, R. Roman, M. Maldonado, R. Goncalves dos Santos, J. Rolon, N. Darabiha, Development of a Diesel-Biodiesel-Ethanol combined chemical scheme and analysis of reactions pathways, Fuel, 191, 411-426 (2017)

4. A. Nirala, CI engine combustion (presentation), https://www.slideshare.net/akhileshroy96/ci-enginecombustion-by-akhileshwar-nirala (2014)

5. C. Sivaroja, G. Sakthivel, Compression Ignition engine performance modeling using hybrid MCDM techniques for the selection of optimum fish oil Biodiesel blend at different injection timings, Energy, 139, 118-141 (2017)

6. H. How, H. Masjuki, M. Kalam, Y. Teoh, Influence of injection timing and split injection strategies on performance, emissions and combustion characteristics of Diesel engine fueled with Biodiesel blended fuels, Fuel, 213, 106-114 (2018)

7. H. Koeten, A. Parlakygit, Effects of the Diesel engine parameters on the ignition delay, Fuel, 216, 23-28 (2018) 
8. M. Musthafa, T. Kumar, T. Mohanraj, R. Chandramouli, A comparative study on performance, combustion and emission characteristics of Diesel engine fueled by Biodiesel blends with and without an additive, Fuel, 225, 343-348 (2018)

9. M. Kumaran, A. Khalid, H. Salleh, A. Razali, A. Sapit, N. Jaat, S. Norshuhaila, Effect of Algae-derived Biodiesel on ignition delay, combustion process and emission, Intl. Eng. Research and Innovation Symposium (IRIS), 160(1) (2016)

10. M. Aldhaidhawi, L. Miron, R. Chiriac, V. Badescu, Autoignition process in compression ignition engine fueled by Diesel fuel and Biodiesel with $20 \%$ rapeseed biofuel Diesel fuel, J. Energy Eng., 144(5) (2018)

11. M. Campbell, D. Davidson, R. Hanson, Scaling relation for high temperature Bio-diesel surrogate ignition delay times, Sandia National Laboratories, Fuel, 164, 151-159 (2016)

12. F. Soto, M. Alves, J. Valdes, O. Armas, P. Crnkovic, G. Rodrigues, A. Lacerda, L. Melo, The determination of the activation energy of Diesel and Biodiesel fuels and the analysis of engine performance and soot emissions, Fuel Processing Technology, 174, 69-77 (2018)

13. M. Aldhaidhawi, Study on performance, emissions and combustion characteristics of a Diesel engine fueled with Biodiesel B20, (PhD Thesis, Politehnica Univesity Bucharest, 2017)

14. D. Assanis, Z. Filipi, S. Fiveland, M. Syrimis, A predictive ignition delay correlation under steadystate and transient operation of a direct-injection Diesel engine, ASME Transactions: J. of Eng. for Gas Turbines and Power, 125(2), 450-457 (2003)

15. M. Aldhaidhawi, A. Racovitza, R. Chiriac, V. Badescu, Ignition delay period for compression ignition engine operating on Diesel and Biodiesel B20, UPB Sci.Bull. Series D, 79(4), 83-94 (2017)

16. J. Livengood, $\mathrm{P}$. $\mathrm{Wu}$, Correlation of autoignition phenomena in internal combustion engines and rapid compression machines, 5th Symp. (Int.) on Combustion, Reinhold Publ. Corp., 347-356 (1955) 